\title{
Description and Interrelationship Analysis of the Phenotypic and Genotypic Characteristics of MSSA and MRSA Strains Isolated From Healthcare Workers in North-eastern Brazil
}

\author{
Maraiza Alves de Oliveira \\ Universidade Federal de Sergipe \\ Yasmin Monara Ferreira Sousa Andrade \\ Oswaldo Cruz Foundation \\ Alisson da Costa Souza \\ Universidade Federal de Sergipe \\ Icaro Bonyek Santos da Silva \\ Oswaldo Cruz Foundation \\ Guilherme Barreto Campos \\ Federal University of Bahia (UFBA), Vitória da Conquista \\ Lucas Miranda Marques \\ Federal University of Bahia (UFBA), Vitória da Conquista \\ Grace Anne Azevedo Doria \\ Universidade Federal de Sergipe \\ Rafael Ciro Marques Cavalcante ( $\sim$ rafaelciro@academico.ufs.br) \\ Universidade Federal de Sergipe
}

Research Article

Keywords: Methicillin-Resistant Staphylococcus aureus, Drug Resistance, Virulence, Biofilm, Healthcare Worker

Posted Date: August 4th, 2021

DOI: https://doi.org/10.21203/rs.3.rs-721934/v1

License: (c) (i) This work is licensed under a Creative Commons Attribution 4.0 International License. Read Full License 


\section{Abstract}

Purpose: This study therefore sought to analyse the interrelationship between the phenotypic and genotypic characteristics of methicillin-susceptible Staphylococcus aureus (MSSA) and MRSA strains isolated from healthcare workers in north-eastern Brazil.

Patients and methods: Staphylococcus aureus strains were isolated from nasal mucosa of nursing professionals. They are identified by biochemical analysis and the sensibility drug test were carried out by agar diffusion method. Biofilm formation was detected on the polystyrene plastic surface. Molecular characterization was conducted by polymerase chain reaction (PCR). The Chi-squared or Fisher's exact tests were applied for the analysis of associations between phenotypic and genotypic characteristics.

Results: A total of 118 workers were involved, $49.15 \%$ of whom presented $S$. aureus. The most frequently observed strain was resistance to penicillin (86.21\%), while the inducible clindamycin resistance (iMLS ${ }_{B}$ ) phenotype was detected in $48.84 \%$ of isolates. MRSA was found in $41.37 \%$ of isolates, while SCCmec type I was seen in $75 \%$. A strain with intermediate resistance to vancomycin was also found. In terms of virulence genes, eta, tst, pvl, spa, clfA, icaA, icaC and icaD genes were detected at least once. Biofilm formation was detected in $89.65 \%$ of the strains $-18.97 \%$ of these were classified as strongly adherent. No associations with ica genes were detected. Multivariate analyses of clusters demonstrated variability between the strains, with the notable formation of three main clusters, according to phenotypic and genotypic characteristics.

Conclusion: High prevalence, multidrug resistance and presence of MRSA strains were all observed. Most isolates had significant virulence genes and the ability to form biofilms, increasing the severity of potential infections. It is therefore necessary to monitor the strains circulating in this hospital and to intensify precautionary measures in order to prevent their spread.

\section{Introduction}

Staphylococcus aureus is associated with endocarditis, bacteremia, osteomyelitis, and skin and soft tissue infections. ${ }^{1}$ The severity of infections caused by this pathogen is intensified when methicillin-resistant Staphylococcus aureus (MRSA) is involved. Resistance occurs through the acquisition of a staphylococcal chromosomal cassette mec (SCCmec), which carries the mecA or mecC gene, encoding an altered penicillin-binding protein (PBP2a) which confers resistance to $\beta$ lactams. ${ }^{2}$ Due to the growing spread of MRSA, there has been an increase in the use of antibiotics from the Macrolide-Lincosamide-Streptogramin $B\left(M L S_{B}\right)$ group, especially clindamycin. ${ }^{3}$ Resistance to this group can be expressed through various mechanisms, which may be constitutive $\left(\mathrm{cMLS}_{\mathrm{B}}\right)$ or inducible $\left(\mathrm{iMLS}_{\mathrm{B}}\right)^{4}$

S. aureus ability to cause infections is related to the production and expression of virulence factors ${ }^{5}$ that favour immune evasion and increase the severity of infections. ${ }^{6}$ These include agglutination factors $A$ and $B{ }^{7}$, biofilm, staphylococcal enterotoxins (SE), toxic shock syndrome toxin 1 (TSST-1), exfoliative toxins, staphylococcal protein A (spa) and Panton-Valentine Leukocidin (pvl). ${ }^{8}$

The pathogen is endemic in a number of hospitals and presents a danger to patients, since they are vulnerable and frequently immunodepressed and thus more susceptible to colonization. ${ }^{9}$ Nursing staff, who have physical proximity to these patients are more susceptible to colonization by this microorganism. ${ }^{10}$ Within the hospital environment, healthcare workers may contribute to

the nosocomial transmission of $S$. aureus as reservoirs or vectors. ${ }^{11}$ Once colonization occurs, nurses become potential spreaders of microorganisms in health services and may cause outbreaks of infection and compromise patient health. ${ }^{12}$ This study was undertaken to analyse the interrelationship of phenotypic and genotypic characteristics of methicillin-susceptible Staphylococcus aureus MSSA and MRSA strains isolated from healthcare workers in northeastern Brazil.

\section{Material And Methods}

An exploratory and cross-sectional study was undertaken with nursing staff from a university hospital in a rural area of Sergipe in north-eastern Brazil. Collections were performed in the hospital between April 2016 and June 2017. Analyses were conducted in the Research Laboratories of the Federal Universities of Sergipe and Bahia between April 2016 and December 2017. The 
Committee for Ethics in Research on Human Beings at the Federal University of Sergipe approved the research under opinion number: 2377921.

\section{Sample collection and Phenotype Identification}

All nursing staff, including technicians and nurses, were invited to participate in the study; a total of 118 accepted. After signing an Informed Consent Form, a questionnaire was applied regarding sex, age, professional experience and occupation. In parallel, samples were collected with nasal swabs using a previously described method ${ }^{13}$, incubated using medium Brain Heart Infusion (BHI, HiMedia, India) with $7.5 \% \mathrm{w} / \mathrm{v} \mathrm{NaCl}$, for 18 to 24 hours at $35^{\circ} \mathrm{C}$ under $200 \mathrm{rpm}$ agitation. Following growth, the samples were seeded on mannitol salt agar (HiMedia, India) and incubated for 18 to 24 hours at $35^{\circ} \mathrm{C}$. Positive mannitol isolates were tested by Gram stain, catalase, coagulase and DNAse. Strains which yielded positive Gram-positive cocci, catalase, DNAse and coagulase were identified as $S$. aureus.

\section{Antimicrobial susceptibility}

Antimicrobial susceptibility was detected through the disk diffusion method described ${ }^{14}$, following the recommendations of the Clinical and Laboratory Standards Institute (CLSI). ${ }^{15}$ Azithromycin $15 \mu \mathrm{g}$, ciprofloxacin $5 \mu \mathrm{g}$, erythromycin $15 \mu \mathrm{g}$, clindamycin 2 $\mu \mathrm{g}$, linezolid $30 \mu \mathrm{g}$, penicillin 10Ul, rifampin $5 \mu \mathrm{g}$ and tetracycline $30 \mu \mathrm{g}$ were tested. Strains resistant to at least three antimicrobial agents were classified as multi-resistant. ${ }^{16}$ Cefoxitin disks $(30 \mu \mathrm{g})$ were used to detect methicillin resistance. The D-test was performed to classify the $\mathrm{MLS}_{\mathrm{B}}$ phenotype in strains resistant to erythromycin. Isolate susceptibility to oxacillin and vancomycin was analysed using the agar dilution technique, in line with CLSI recommendations. ${ }^{15}$ S. aureus ATCC 25923 was used as a control strain.

\section{Biofilm Formation}

The ability to form biofilm on plates was assessed using the methodology described. ${ }^{17}$ Bacterial suspensions with turbidity equivalent to 0.5 on the McFarland scale were diluted in BHI at 1: 100, in a flat-bottomed polystyrene plate with 96 wells (Kasvi, Brazil) to a final volume of $200 \mu \mathrm{L}$ and incubated at $37^{\circ} \mathrm{C}$ for $24 \mathrm{~h}$. The plate was then inverted and rinsed three times with distilled water to remove non-adherent cells. Two hundred $\mu \mathrm{L}$ of $99 \%$ methanol was then added and the plates were emptied and dried 15 minutes later. Two hundred $\mu \mathrm{L}$ of $2 \%$ crystal violet $(\mathrm{w} / \mathrm{v})$ were added to each well, and the plates were again incubated for 5 minutes at $37^{\circ} \mathrm{C}$. Following this, the plate was again inverted, rinsed and dried by inversion. The dye bound to the adhered cells was resolubilized with $150 \mu \mathrm{L}$ of $33 \%$ acetic acid $(\mathrm{v} / \mathrm{v})$ and $125 \mu \mathrm{L}$ were transferred from each well to a new plate. The biofilm formation was measured through an absorbance reading at $600 \mathrm{~nm}$ in a microtiter plate reader (Thermo Scientific Multiskan EX). The tests were performed in triplicate. S. aureus ATCC 29213 and sterile BHI were used as positive and negative controls respectively. The strains were classified as Non-Adherent (NA), Weak Adherent (WA), Moderate Adherent (MA) and Strong Adherent (SA), in line with previously established criteria. ${ }^{18}$

\section{Molecular Characterization}

The total DNA was extracted by boiling, using a protocol adapted. ${ }^{19}$ Bacterial suspensions were centrifuged at $14,000 \mathrm{rpm}$ for 15 minutes to obtain a pellet. The pellet was then rinsed twice and re-suspended in $100 \mu \mathrm{L}$ of Phosphate-Buffered Saline 1X (PBS). The bacterial suspension was exposed to a heat shock of $100^{\circ} \mathrm{C}$ for 10 minutes, then $0^{\circ} \mathrm{C}$ for 5 minutes. DNA concentration and purity were measured using a NanoDrop UV-Vis spectrophotometer (Thermo Fisher Scientific, USA). Conventional Polymerase Chain Reaction (PCR) was used to detect the mecA gene, using a primer described by ${ }^{20}$, and the pvl ${ }^{21}$, eta, tst ${ }^{22}$, spa $^{23}$, clfA ${ }^{24}$, icaA, icaD and icaC ${ }^{25}$ virulence genes. Positive mecA strains were subject to a multiplex PCR reaction to amplify the genes from chromosomal cassettes I to $\mathrm{V}$, using previously described primers and methods. ${ }^{26}$ The reactions were prepared in $25 \mu \mathrm{L}$, containing: $12.5 \mu \mathrm{L}$ Master Mix (Promega, USA), $1 \mu \mathrm{L}$ of each primer, $2.5 \mu \mathrm{L}$ of DNA template and enough ultrapure water to a total of $25 \mu \mathrm{L}$. The amplifications were performed according to conditions established by the authors of each primer. These were performed in a thermal cycler (Bio-Rad®, model T100TM) and the products were visualized by electrophoresis in $2 \%$ agarose gel in a 1X Tris-Acetate-EDTA (TAE) buffer. Finally, the gels were stained with ethidium bromide, visualized and photo-documented (UVP-Multidoc-lt digital imaging system, USA). 


\section{Multivariate analyses for grouping data}

Data regarding strain clusters, according to genotypic and phenotypic characteristics, were represented through heat maps and principal components analysis (PCA). Isolates were analysed using http://www.heatmapper.ca/expression/, where unsupervised hierarchical grouping was performed using average distance and Euclidean distance as metrics, and https://cytoscape.org/ (version 3.8.2) to assess the interrelationships between components.

\section{Statistical analysis}

Statistical analyses of the results were performed using SPSS 16.0 software (SPSS Inc., Chicago, IL, USA). The Chi-squared or Fisher's exact tests were applied for the analysis of association. The latter was only applied when the expected frequencies were below five. Differences between means presenting $p<0.05$ were considered significant.

\section{Results}

In total, 118 samples were collected and 58 isolates were identified as $S$. aureus (49.15\%). Most isolates were from female nursing technicians (79.3\%), under 40 years old (69.0\%), with five or more years of professional experience (Table 1). The univariate analysis demonstrated no significant association between carrier status and demographic characteristics.

Table 1

DEMOGRAPHIC CHARACTERISTICS OF VOLUNTEERS AND DISTRIBUTION OF CARRIERS AND NON-CARRIERS

\begin{tabular}{|llll|}
\hline Variables & & Non-carrier & Carrier \\
\hline Sex & Female & $\mathbf{N = 6 0 \%}$ & $\mathbf{N}=\mathbf{5 8} \%$ \\
\cline { 2 - 4 } & Male & $53(88.3)$ & $46(79.3)$ \\
\hline Age & $<40$ years & $7(11.7)$ & $12(20.7)$ \\
\cline { 2 - 4 } & $\geq 40$ years & $39(65.0)$ & $40(69.0)$ \\
\hline Professional Experience & $<5$ years & $21(35.0)$ & $18(31.0)$ \\
\cline { 2 - 4 } & $\geq 5$ years & $18(30.0)$ & $17(29.3)$ \\
\hline Occupation & Nurse & $42(70.0)$ & $41(70.7)$ \\
\cline { 2 - 4 } & Nursing technician & $34(56.7)$ & $35(60.3)$ \\
\hline No differences were observed in the frequency of carriers and non-carriers (p value $0.14-0.93)$. \\
\hline
\end{tabular}

\section{Antimicrobial susceptibility}

The isolates were more frequently resistant to penicillin (86.21\%), erythromycin (74.14\%), azithromycin (67.24\%) and ciprofloxacin $(53.45 \%)$ and less frequently to tetracycline (36.21\%), clindamycin (19.87\%), rifampicin (12.07\%), and linezolid (1.72\%). Multidrug resistance was present in $42(72.41 \%)$ isolates. The $\mathrm{MLS}_{\mathrm{B}}$ phenotype was observed in 43 isolates. Of these, eleven (25.58\%) were resistant to clindamycin, as detected by disk diffusion, and were therefore classified as $\mathrm{CMLS}_{B}$, while $21(48.84 \%)$ were iMLS $\mathrm{B}_{B}$ positive. Resistance to methicillin was found via disk diffusion in $25.58 \%$ of isolates, while through the agar dilution test the figure was $34.38 \%$. One strain with intermediate resistance to vancomycin was also found.

\section{Methicillin resistance}

The mecA gene was detected in $41.37 \%$ of the isolates (24/58). Detections via disk diffusion and agar dilution reached $62.50 \%$ and $83.33 \%$ sensitivity, respectively, with $79.07 \%$ and $89.47 \%$ Negative Predictive Values. Specificity and Positive Predictive Values obtained $100 \%$. The resistance index for the azithromycin, ciprofloxacin, erythromycin and tetracycline antimicrobials was significantly higher among the MRSA strains (Fig. 1). In the SCCmectyping, the highest frequency was SCCmec type I, found in 18 
of the 24 MRSA isolates (75.00\%), followed by SCCmec type III (12.50\%), SCCmec type V (8.33\%) and SCCmec type IV (4.17\%). SCCmec type II was not found. Of the 24 MRSA strains, 23 had different genotypic and phenotypic profiles (Table 3 ).

Table 3

PHENOTYPIC AND GENOTYPIC PROFILE OF MRSA STRAINS ISOLATED FROM NURSING STAFF, BRAZIL

\begin{tabular}{|c|c|c|c|c|c|}
\hline \multirow{2}{*}{$\begin{array}{l}\text { Isolate } \\
n=24\end{array}$} & \multicolumn{3}{|l|}{ Phenotypic Profile } & \multicolumn{2}{|c|}{ Genotypic Profile } \\
\hline & Antimicrobial Resistance & MLSB Phenotype & Biofilm formation & Virulence & scCmec type \\
\hline $\mathrm{C} 44$ & PEN & * & WA & icaAC & I \\
\hline $\mathrm{C} 46$ & PEN & * & WA & spa, clfA, icaA & I \\
\hline $\mathrm{C} 27$ & AZM CIP ERY PEN & MS & NA & eta, icaC & IV \\
\hline $\mathrm{C} 11$ & AZM ERY PEN & $\mathrm{iMLS}_{\mathrm{B}}$ & SA & icaADC & I \\
\hline C35 & AZM ERY PEN & $\mathrm{iMLS}_{\mathrm{B}}$ & SA & eta, icaADC & 1 \\
\hline C32 & AZM ERY PEN TET & $\mathrm{iMLS}_{\mathrm{B}}$ & WA & clfA, icaC & I \\
\hline C34 & AZM CIP ERY PEN & MS & MA & spa, icaD & III \\
\hline C52 & AZM CIP ERY PEN & MS & MA & clfA, icaADC & I \\
\hline C54 & AZM CIP ERY PEN & $\mathrm{iMLS}_{\mathrm{B}}$ & MA & - & I \\
\hline C4 & AZM CIP ERY PEN TET & $\mathrm{iMLS}_{\mathrm{B}}$ & MA & spa & 1 \\
\hline C15/C58 & AZM CIP ERY PEN TET & $\mathrm{iMLS}_{\mathrm{B}}$ & MA & - & I \\
\hline $\mathrm{C} 28$ & AZM CIP ERY PEN TET & $\mathrm{iMLS}_{\mathrm{B}}$ & SA & spa, clfA, icaC & 1 \\
\hline C39 & AZM CIP ERY PEN TET & $\mathrm{iMLS}_{\mathrm{B}}$ & NA & spa, clfA, icaD & I \\
\hline C17 & AZM CLI ERY PEN TET & $\mathrm{cMLS}_{\mathrm{B}}$ & MA & icaADC & III \\
\hline C18 & AZM CLI ERY PEN TET & $\mathrm{CMLS}_{\mathrm{B}}$ & NA & $i c a C$ & I \\
\hline C19 & CIP CLI ERY PEN TET & $\mathrm{cMLS}_{\mathrm{B}}$ & WA & spa & I \\
\hline C50 & AZM CIP ERY LZD PEN RIF & MS & WA & icaAC & V \\
\hline C51 & AZM CIP ERY PEN RIF TET & MS & SA & $c l f A, i c a A C$ & 1 \\
\hline C56 & AZM CIP ERY PEN RIF TET & MS & MA & clfA, icaADC & I \\
\hline C40 & AZM CIP CLI ERY PEN TET & $\mathrm{cMLS}_{\mathrm{B}}$ & NA & clfA, icaA & III \\
\hline C53 & AZM CIP CLI ERY PEN TET & $\mathrm{cMLS}_{\mathrm{B}}$ & SA & $i c a A D$ & I \\
\hline C55 & AZM CIP CLI ERY PEN TET & $\mathrm{cMLS}_{\mathrm{B}}$ & MA & spa, icaAD & V \\
\hline $\mathrm{C} 45$ & AZM CIP ERY PEN RIF TET & MS & WA & spa, icaDC & 1 \\
\hline \multicolumn{6}{|c|}{ 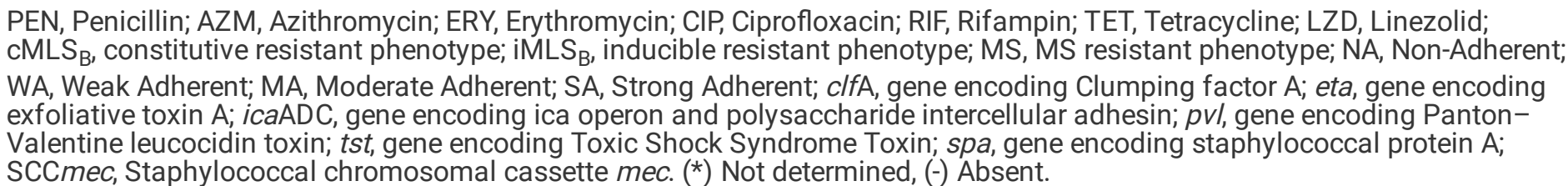 } \\
\hline
\end{tabular}


PEN, Penicillin; AZM, Azithromycin; ERY, Erythromycin; CIP, Ciprofloxacin; RIF, Rifampin; TET, Tetracycline; LZD, Linezolid; MRSA, methicillin-resistant Staphylococcus aureus, MSSA, methicillin-susceptible S. aureus. *statistically significant $(p$ value < 0.05$)$.

\section{Note}

MRSA isolates are considered resistant to penicillin, statistics not applicable.

\section{Biofilm Formation}

Formation of biofilm on plates was confirmed in $89.65 \%$ (52) of the strains. Of these, $18.97 \%(11 / 58)$ were classified as SA, $32.76 \%$ (19/58) MA, 37.93\% (22/58) WA, while 10.34\% (6/58) were classified as NA. The distribution of resistance and biofilm

formation phenotypes among the isolates can be found in Table 2 . The univariate analysis demonstrated that iMLS $\mathrm{B}_{\mathrm{B}}$ are strong biofilm-forming strains $(p=0.035)$. Similarly, isolates that did not have an association with icaA, icaC or icaD genes did not form biofilms $(p=0.044)$. 
PHENOTYPES OF RESISTANCE AND BIOFILM FORMATION IN S. aureUs ISOLATED FROM NURSING STAFF, BRAZIL

\begin{tabular}{|c|c|c|c|c|c|c|c|c|c|c|c|c|c|c|c|c|}
\hline Isolate & AZM & CIP & CLI & ERY & FOX & LZD & PEN & RIF & TET & $\mathrm{iMLS}_{\mathrm{B}}$ & $\mathrm{cMLS}_{\mathrm{B}}$ & MS & NA & WA & MA & SA \\
\hline C1 & 1 & & & 1 & & & 1 & & & 1 & & & & & 1 & \\
\hline C2 & 0 & 1 & & & & & & & & & & & & & 1 & \\
\hline C3 & 0 & & & & & & & & & & & & & & & 1 \\
\hline C4 & 1 & 1 & & 1 & & & 1 & & 1 & 1 & & & & & 1 & \\
\hline C5 & 1 & & & & & & & & & & & & & & 1 & \\
\hline C6 & 1 & & & & & & 1 & & & & & & & 1 & & \\
\hline C7 & 0 & 1 & & & & & 1 & & & & & & & & 1 & \\
\hline C8 & 0 & 1 & & & & & 1 & & 1 & & & & & & & 1 \\
\hline C9 & 1 & 1 & & 1 & & & 1 & & & 1 & & & & & 1 & \\
\hline C10 & 0 & 1 & & 1 & & & 1 & & & 1 & & & & 1 & & \\
\hline C11 & 1 & & & 1 & & & 1 & & & 1 & & & & & & 1 \\
\hline C12 & 0 & & & 1 & & & 1 & & & 1 & & & & & & 1 \\
\hline C13 & 0 & 1 & 1 & 1 & & & 1 & 1 & & & 1 & & & & 1 & \\
\hline C14 & 0 & 1 & 1 & 1 & & & & & 1 & & 1 & & & 1 & & \\
\hline C15 & 1 & 1 & & 1 & & & 1 & & 1 & 1 & & & & & 1 & \\
\hline C16 & 1 & 1 & 1 & 1 & & & 1 & & 1 & & 1 & & & 1 & & \\
\hline C17 & 1 & & 1 & 1 & 1 & & 1 & & 1 & & 1 & & & & 1 & \\
\hline C18 & 1 & & 1 & 1 & & & 1 & & 1 & & 1 & & 1 & & & \\
\hline C19 & 0 & 1 & 1 & 1 & & & 1 & & 1 & & 1 & & & 1 & & \\
\hline C2O & 0 & & & & 1 & & 1 & & & & & & & 1 & & \\
\hline C21 & 1 & 1 & & 1 & & & & & & 1 & & & & & & 1 \\
\hline C22 & 1 & 1 & & 1 & & & 1 & & 1 & 1 & & & & 1 & & \\
\hline C23 & 0 & 1 & & & & & 1 & & & & & & & 1 & & \\
\hline C24 & 1 & & & 1 & & & 1 & & & 1 & & & & 1 & & \\
\hline C25 & & & & & & & 1 & & & & & & & 1 & & \\
\hline C26 & 1 & & & 1 & & & 1 & & & 1 & & & & 1 & & \\
\hline C27 & 1 & 1 & & 1 & & & 1 & & & & & 1 & 1 & & & \\
\hline C28 & 1 & 1 & & 1 & 1 & & 1 & & 1 & 1 & & & & & & 1 \\
\hline C29 & & 1 & 1 & 1 & & & & & 1 & & 1 & & & & 1 & \\
\hline C30 & 1 & & & 1 & & & 1 & & & 1 & & & & & & 1 \\
\hline C31 & 1 & & & 1 & & & 1 & & & 1 & & & & 1 & & \\
\hline C32 & 1 & & & 1 & 1 & & 1 & & 1 & 1 & & & & 1 & & \\
\hline C33 & 1 & & & 1 & & & 1 & & & & & 1 & & 1 & & \\
\hline
\end{tabular}




\begin{tabular}{|c|c|c|c|c|c|c|c|c|c|c|c|c|c|c|c|c|}
\hline Isolate & AZM & CIP & CLI & ERY & FOX & LZD & PEN & RIF & TET & $\mathrm{iMLS}_{\mathrm{B}}$ & $\mathrm{cMLS}_{\mathrm{B}}$ & MS & NA & WA & MA & SA \\
\hline C34 & 1 & 1 & & 1 & & & 1 & & & & & 1 & & & 1 & \\
\hline C35 & 1 & & & 1 & 1 & & 1 & & & 1 & & & & & & 1 \\
\hline C36 & & 1 & & 1 & & & 1 & & & 1 & & & & & & 1 \\
\hline C37 & 1 & & & 1 & & & & & & & & 1 & & 1 & & \\
\hline C38 & & & & & & & 1 & & & & & & 1 & & & \\
\hline C39 & 1 & 1 & & 1 & 1 & & 1 & & 1 & 1 & & & 1 & & & \\
\hline C40 & 1 & 1 & 1 & 1 & 1 & & 1 & & 1 & & 1 & & 1 & & & \\
\hline C41 & 1 & & & & & & 1 & & & & & & 1 & & & \\
\hline C42 & 1 & & 1 & 1 & & & 1 & & & & 1 & & & 1 & & \\
\hline C43 & 1 & 1 & & 1 & & & 1 & & 1 & & & 1 & & 1 & & \\
\hline C44 & & & & & 1 & & 1 & & & & & & & 1 & & \\
\hline C45 & 1 & 1 & & 1 & 1 & & 1 & 1 & 1 & & & 1 & & 1 & & \\
\hline C46 & & & & & & & 1 & & & & & & & 1 & & \\
\hline C47 & & & & & & & & 1 & & & & & & 1 & & \\
\hline C48 & & & & & & & 1 & & & & & & & & 1 & \\
\hline C49 & 1 & & & 1 & & & 1 & & & 1 & & & & & 1 & \\
\hline C50 & 1 & 1 & & 1 & 1 & 1 & 1 & 1 & & & & 1 & & 1 & & \\
\hline C51 & 1 & 1 & & 1 & 1 & & 1 & 1 & 1 & & & 1 & & & & 1 \\
\hline C52 & 1 & 1 & & 1 & 1 & & 1 & & & & & 1 & & & 1 & \\
\hline C53 & 1 & 1 & 1 & 1 & 1 & & 1 & & 1 & & 1 & & & & & 1 \\
\hline C54 & 1 & 1 & & 1 & & & 1 & & & 1 & & & & & 1 & \\
\hline C55 & 1 & 1 & 1 & 1 & 1 & & 1 & & 1 & & 1 & & & & 1 & \\
\hline C56 & 1 & 1 & & 1 & 1 & & 1 & 1 & 1 & & & 1 & & & 1 & \\
\hline C57 & 1 & & & 1 & & & 1 & 1 & & & & 1 & & & 1 & \\
\hline C58 & 1 & 1 & & 1 & & & 1 & & 1 & 1 & & & & & 1 & \\
\hline
\end{tabular}

\section{Virulence Genotype}

The most frequently found virulence gene was icaA, which was detected in $62.07 \%(36 / 58)$ of the isolates, while the least common virulence gene was $\mathrm{pvl}$, which was present in only one (1.72\%). There was a difference in the distribution of genes between the MRSA and MSSA isolates and the distribution of icaD was significantly lower among the methicillin-resistant (Table 4). Forty-two isolates had more than one virulence gene, while three isolates harboured six (Table 5). 
Table 4

DISTRIBUTION OF VIRULENCE GENES IN METHICILLIN-SUSCEPTIBLE AND METHICILLIN-RESISTANT S. aureus, ISOLATED FROM NURSING STAFF

\begin{tabular}{|c|c|c|c|c|}
\hline \multirow[t]{2}{*}{ Virulence gene } & MRSA \% & MSSA \% & Total \% & \multirow[t]{2}{*}{ p value* } \\
\hline & $\mathrm{n}=24$ & $\mathrm{n}=34$ & $\mathrm{n}=58$ & \\
\hline clfA & $33.33(8)$ & $38.23(13)$ & $36.21(21)$ & $0.7020 \dagger$ \\
\hline eta & $8.33(2)$ & 0 & $3.45(2)$ & $0.1670 \mathbb{8}$ \\
\hline ica & $50.00(12)$ & $70.58(24)$ & $62.07(36)$ & $0.1115+$ \\
\hline icaC & $54.26(13)$ & $64.70(22)$ & $60.34(35)$ & $0.4190 \dagger$ \\
\hline icaD & $41.66(10)$ & $73.53(25)$ & $60.34(35)$ & $0.0146 t$ \\
\hline spa & $16.66(4)$ & $35.29(12)$ & $27.59(16)$ & $0.1180+$ \\
\hline$p v l$ & $4.16(1)$ & 0 & $1.72(1)$ & $0.4138 \rrbracket$ \\
\hline tst & 0 & $5.88(2)$ & $3.45(2)$ & $0.5064 \rrbracket$ \\
\hline \multicolumn{5}{|c|}{$\begin{array}{l}\text { MRSA, methicillin-resistant Staphylococcus aureus; MSSA, methicillin-susceptible } S \text {. aureus, clfA, gene encoding Clumping } \\
\text { factor A; eta, gene encoding exfoliative toxin A; icaADC, gene encoding ica operon and polysaccharide intercellular adhesin; } \\
\text { pvl, gene encoding Panton-Valentine leucocidin toxin; tst, gene encoding Toxic Shock Syndrome Toxin; spa, gene encoding } \\
\text { staphylococcal protein A. * p value in bold indicates statistical significance }(\mathrm{p}<0.05) \text {. }\end{array}$} \\
\hline \multicolumn{5}{|l|}{ † Chi-squared test } \\
\hline Q Fisher's exact test & & & & \\
\hline
\end{tabular}


CO-EXISTENCE OF S. aureus VIRULENCE GENES ISOLATED FROM NURSING STAFF IN LAGARTO, BRAZIL

\begin{tabular}{|c|c|}
\hline Genes & $\mathrm{n} \%$ \\
\hline$c l f a+i c a C$ & $2(3.45)$ \\
\hline$c l f a+i c a D$ & $2(3.45)$ \\
\hline eta $+i c a C$ & $1(1.72)$ \\
\hline$i c a A+i c a C$ & $3(5.17)$ \\
\hline$i c a \mathrm{~A}+i c a \mathrm{D}$ & $3(5.17)$ \\
\hline$i c a \mathrm{C}+i c a \mathrm{D}$ & $1(1.72)$ \\
\hline$i c a \mathrm{~A}+i c a \mathrm{C}+i c a \mathrm{D}$ & $8(13.79)$ \\
\hline$c l f a+i c a a A+i c a C$ & $1(1.72)$ \\
\hline$c l f a+i c a a A+i c a D$ & $1(1.72)$ \\
\hline$c l f a+s p a+i c a A$ & $2(3.45)$ \\
\hline$s p a+i c a \mathrm{~A}+i c a \mathrm{C}$ & $1(1.72)$ \\
\hline$s p a+i c a \mathrm{~A}+i c a \mathrm{C}$ & $1(1.72)$ \\
\hline$s p a+i c a \mathrm{~A}+i c a \mathrm{D}$ & $2(3.45)$ \\
\hline$c l f a+i c a A+i c a C+i c a D$ & $4(6.90)$ \\
\hline$c l f a+s p a+i c a A+i c a D$ & $1(1.72)$ \\
\hline$s p a+i c a \mathrm{~A}+i c a \mathrm{C}+i c a \mathrm{D}$ & $2(3.45)$ \\
\hline$c l f a+s p a+i c a A+i c a C+i c a D$ & $4(6.90)$ \\
\hline eta $+s p a+i c a \mathrm{~A}+i c a \mathrm{C}+i c a \mathrm{D}$ & $1(1.72)$ \\
\hline$c l f a+p v l+s p a+i c a \mathrm{~A}+i c a \mathrm{C}+i c a \mathrm{D}$ & $1(1.72)$ \\
\hline$c l f a+s p a+t s t+i c a \mathrm{~A}+i c a \mathrm{C}+i c a \mathrm{D}$ & $2(3.45)$ \\
\hline \multicolumn{2}{|c|}{$\begin{array}{l}\text { clfA, gene encoding Clumping factor A; eta, gene encoding exfoliative toxin A; icaADC, gene encoding ica operon and } \\
\text { polysaccharide intercellular adhesin; } p v l \text {, gene encoding Panton-Valentine leucocidin toxin; } t s t \text {, gene encoding Toxic Shock } \\
\text { Syndrome Toxin; spa, gene encoding staphylococcal protein A. }\end{array}$} \\
\hline
\end{tabular}

\section{S. aureus strain clustering}

Based on our data, the interrelationship and clustering of $S$. aureus strains can be found in Fig. 2. The heat maps show that different clusters (groups) were formed for strains with similar characteristics in terms of resistance (a), virulence (b) and the whole dataset (phenotypic and genotypic). The PCA analysis reinforces the heat map results, demonstrating the formation of different groups according to the above-mentioned characteristics: resistance (d), virulence (e) and for the whole dataset (phenotypic and genotypic). This data therefore demonstrates the diversity of $S$. aureus strains isolated from healthcare workers, as highlighted by the formation of 3 main groups.

\section{Discussion}

As far as we are aware, this is the first report that demonstrates the phenotypic and genotypic profiles of $S$. aureus resistance and virulence isolated from nursing staff and undertaken in Sergipe, Brazil. Knowledge about colonization in healthcare workers supports the development of infection control strategies. ${ }^{27}$ The general prevalence of $S$. aureus found in this study was $49.15 \%$. Collecting samples from healthcare workers in a university hospital, obtained a prevalence of $25.7 \%{ }^{28}$ Furthermore, in a study of nursing staff working in specialized HIV units, obtained a similar prevalence (22.9\%). ${ }^{29}$ However, a study of working with 
healthcare workers in an urban university hospital, recorded a prevalence of $43.8 \%,{ }^{30}$ similar to that found here. These variations may be related to the patient population, natural microbiota on skin or collection procedures. ${ }^{31}$

Multidrug resistant bacteria are difficult to treat and treatment results are less effective than for susceptible bacteria. ${ }^{32}$ Multidrug resistance was found in $72.41 \%$ of isolates in this study, principally to penicillin, erythromycin and azithromycin. In the same way, in a study of healthcare workers in a children's hospital in Iran, found high levels of resistance to these drugs. ${ }^{33}$ In Nepal, analysing clinical samples from infections in children, a high level of resistance was also observed. ${ }^{34}$ However, when analysing isolates from general clinical patients in Austria, researchers found low resistance to azithromycin and erythromycin. ${ }^{35}$ This may at least partially be explained by the duration of drug use, in addition to drug availability in pharmacies and potential irrational use. It is worth noting that knowledge about the profile of $S$. aureus susceptibility to antimicrobials supports the choice and use of antimicrobial agents. ${ }^{36}$

On the other hand, when we used a conventional antibiogram, we observed low levels of resistance to clindamycin (19.87\%). In a similar way, in a study of healthcare workers in a university hospital in Nepal, researchers found a $6.3 \%$ resistance level. ${ }^{37}$ Another study, found that $17.2 \%$ of strains were resistant to clindamycin in healthcare workers in two hospitals in Ethiopia. ${ }^{38}$ In our study, the $\mathrm{iMLS}_{\mathrm{B}}$ phenotype was found in $48.84 \%$ of isolates. Researchers obtained $45.5 \%$, which is similar to our finding. ${ }^{37}$ However, in a study of healthcare workers in four hospitals in Tanzania, found $32.5 \%$ positive iMLS $_{B}$ strains, lower than the level detected here. ${ }^{39}$ We therefore note that this level varies and depends on the population studied. ${ }^{3}$ This finding is important, since it emphasizes that when only using conventional antibiograms, many strains are falsely identified as sensitive to clindamycin, leading to the ineffective treatment of infections. ${ }^{40}$

In our study, $41.37 \%$ of $S$. aureus isolates were characterized as MRSA strains. Similarly, collecting samples from healthcare workers in a university hospital in Nepal, researchers obtained an MRSA prevalence of $41.3 \%{ }^{41}$ However, in a study of healthcare workers in a public hospital in north-eastern Brazil, an index of $16.9 \%$ was obtained, lower than that detected here. ${ }^{28}$ Further, in a study undertaken with healthcare workers in a university hospital in Kenya, researchers did not find MRSA. ${ }^{42}$ We therefore note the variability in levels between these populations. The high level found here is important, given that methicillin-resistant Staphylococcus aureus infections are hard to resolve, due to a lack of therapeutic options ${ }^{43}$. In a meta-analysis of 127 studies, was reported that transmission of MRSA to patients was probable in $93 \%$ of studies. ${ }^{44}$ Here, $75 \%$ of isolates were SCCmec type I, while $12.5 \%$ were type III. In the same way, researchers in north-eastern Brazil found that SCCmec I was the most prevalent (40\%). ${ }^{28}$ However the most frequently isolated MRSA clone in Brazil is Brazilian Endemic Clone (BEC) which is SCC mec-III (ST239). ${ }^{45}$ This suggests the circulation of different ST239 clones, which may indicate an, at least partial, replacement of this strain in Brazil. One strain found among the isolates was VISA (1.72\%). This percentage agrees with the meta-analysis, which reported a prevalence of $1.0 \%$ among $S$. aureus isolates in the United States. ${ }^{46}$

S. aureus is frequently linked to infections associated with biomaterials, due to the production of biofilm. ${ }^{47}$ Here, $89.65 \%$ of isolates were biofilm producers. Another study obtained a slightly lower level (72.83\%) when analysing clinical isolates from three hospitals in Thailand. ${ }^{48}$ In our study, there was no significant association between harbouring ica operon genes and intensity of biofilm formation. Other researchers did not observe any such relationship when analysing isolates from bovine mastitic milk. ${ }^{49}$ In the same way, observed biofilm formation in the absence of these genes. ${ }^{50}$ It has therefore been suggested that other genes, in addition to the components of the ica operon, are involved in biofilm formation in these strains. ${ }^{51}$ The isolates high biofilmforming ability is worth noting, since it promotes adhesion to surfaces, clogs medical devices and causes infections tolerant to multiple drugs. ${ }^{52}$

In relation to the virulence genes in the isolates, clfA was detected in $36.21 \%$ of $S$. aureus, more than that found by similar study (8.3\%). ${ }^{28}$ The spa gene was detected in $25.86 \%$ of the $S$. aureus in this study. When analysing isolates from doctors, nurses and laboratory scientists in a reference hospital in Zambia, researchers obtained an almost equal amount (25.8\%). ${ }^{53}$ Nevertheless, a previous study cited, obtained a lower level among nasal isolates (3.3\%). ${ }^{28}$ One isolate (1.72\%) harboured pvl. Other researchers did not find $p v /$ positive strains in isolates from healthcare workers in a hospital centre in Portugal. ${ }^{54}$ In contrast, a study detected 
the gene in $38 \%$ of isolates from workers in an intensive care unit in a Greek hospital. ${ }^{55}$ The tst gene was detected in $3.45 \%$ of isolates. Similarly, in the Czech Republic, found tst in $1.7 \%$ of isolates from patients in a university hospital. ${ }^{56}$ On the other hand, researchers obtained higher prevalence rates (43.3\%) when working with nursing staff in a hospital in Iran. ${ }^{57}$ The presence of multiple virulence genes found here is significant, since the more virulence factors the pathogen expresses, the greater its capacity to cause infection, ${ }^{58}$ It is worth noting that one of the spa positive isolates also harboured $p v l$, which, in association with spa, may cause fatal pneumonia. ${ }^{59}$

Based on the similarity between genotypic and phenotypic factors, strains of $S$. aureus were grouped and different clusters formed, demonstrating variation in the isolates we assessed. Studies which have made more in-depth analyses of the molecular aspects of MSSA and MRSA isolates from hospitals have also demonstrated diversity among these strains, alerting researchers to the role of healthcare workers as sources for the spread of more virulent and/or resistant strains within the hospital environment, and consequently to the risk of spread to the community. ${ }^{28,60}$ The emergence of variable, more virulent or resistant strains hinders the treatment of infections and demonstrates the evolution and adaptability of these bacteria as a result of the exertion of selective pressure, principally in hospitals. ${ }^{28}$ We therefore note the need for studies such as ours, which demonstrate the importance of understanding these microorganisms, in order to prevent spread and infection.

\section{Conclusion}

We observed high prevalence, multidrug resistance and the presence of MRSA strains. We also noticed that phenotypic tests to detect methicillin resistance may generate false negatives and should therefore be linked to molecular analysis. Additionally, we found numerous strains containing the $\mathrm{iMLS}_{\mathrm{B}}$ phenotype, emphasizing the importance of performing the $\mathrm{D}$ test before use of clindamycin. The majority of the isolates carried important virulence genes and had the ability to produce biofilm, increasing the severity of infections they could cause. This study therefore supplements knowledge about strains that circulate in hospitals, highlighting the need to monitor the strains circulating within this hospital and to intensify precautionary measures in order to prevent the spread of these strains.

\section{Abbreviations}

AZM - Azithromycin, BHI - Brain Heart Infusion, BEC - Brazilian Endemic Clone, CIP - Ciprofloxacin, CLSI - Clinical and Laboratory Standards Institute, PCR - Conventional Polymerase Chain Reaction, ERY - Erythromycin, LZD - Linezolid, MLSB - MacrolideLincosamide-Streptogramin B, cMLSB - Macrolide-Lincosamide-Streptogramin B constitutive, iMLSB - Macrolide-LincosamideStreptogramin B inducible, MRSA - methicillin-resistant Staphylococcus aureus, MA - Moderate Adherent, NA - Non-Adherent, PVL Panton-Valentine Leukocidin, PEN - Penicillin, PBP2a - penicillin-binding protein, PCA - principal components analysis, RIF Rifampin, SCCmec - staphylococcal chromosomal cassette mec, SE - staphylococcal enterotoxins, SPA - staphylococcal protein A, SA - Strong Adherent, TET - Tetracycline, TSST-1 - toxic shock syndrome toxin 1, WA - Weak Adherent.

\section{Declarations}

\section{Ethics approval and consent to participate}

The Committee for Ethics in Research on Human Beings at the Federal University of Sergipe approved the research under protocol number: 2377921. The participating professionals, aware of the procedures performed and the research objectives, signed the Informed Consent Term (FICF) and only then were admitted.

\section{Consent for publication}

Not applicable.

\section{Availability of data and material}

Data analyzed during this study are included in this article. Sensitive data of participant are stored confidentially. 


\section{Competing interests}

The authors declare that there is no conflict of interest.

\section{Funding}

No funding.

\section{Authors contributions}

Cavalcante RCM, Doria GAA and Marques LM coordinate the research. Oliveira MA, Andrade YMFS, Sousa AC and Campos GB collected the samples, performed the experiments, analyzed the data and wrote the main manuscript text. Silva IBS prepared figures 1-2. All authors critically reviewed the manuscript.

\section{Acknowledgements}

We would like to thank Caline Novais Teixeira Oliveira, Rodrigo Almeida Simões and Rita de Cassia Santa Rosa Matos for the technical assistance they provided.

\section{References}

1. Turner NA, Sharma-Kuinkel BK, Maskarinec SA, et al. Methicillin-resistant Staphylococcus aureus: an overview of basic and clinical research. Nat Rev Microbiol. 2019;17(4):203-218.

2. Liu J, Chen D, Peters BM, et al. Staphylococcal chromosomal cassettes mec (SCCmec): A mobile genetic element in methicillin-resistant Staphylococcus aureus. Microb Pathog. 2016;101:56-67.

3. Sasirekha B, Usha MS, Amruta JA, Ankit S, Brinda N, Divya R. Incidence of constitutive and inducible clindamycin resistance among hospital-associated Staphylococcus aureus. 3 Biotech. 2014;4(1):85-89.

4. Mwambi B, Iramiot J, Bwanga F, Nakaye M, Itabangi H, Bazira J. Clindamycin Resistance among Staphylococcus aureus Isolated at Mbarara Regional Referral Hospital, in South Western Uganda. Br Microbiol Res J. 2014;4(12):1335-1344.

5. Ghasemian A, Peerayeh SN, Bakhshi B, Mirzaee M. The microbial surface components recognizing adhesive matrix molecules (MSCRAMMs) genes among clinical isolates of Staphylococcus aureus from hospitalized children. Iran J Pathol. 2015;10(4):258-264.

6. González-Martín M, Corbera JA, Suárez-Bonnet A, Tejedor-Junco MT. Virulence factors in coagulase-positive staphylococci of veterinary interest other than Staphylococcus aureus. Vet Q. 2020;40(1):118-131.

7. Gnanamani A, Hariharan P, Paul-Satyaseela M. Staphylococcus aureus: Overview of Bacteriology, Clinical Diseases, Epidemiology, Antibiotic Resistance and Therapeutic Approach. In: Frontiers in Staphylococcus aureus. 2017.

8. Liu C, Chen Z ju, Sun Z, et al. Molecular characteristics and virulence factors in methicillin-susceptible, resistant, and heterogeneous vancomycin-intermediate Staphylococcus aureus from central-southern China. J Microbiol Immunol Infect. 2015;48(5):490-496.

9. McGuinness WA, Malachowa N, DeLeo FR. Vancomycin resistance in Staphylococcus aureus. Yale J Biol Med. 2017;90(2):269-281.

10. Lopes LP, Pio DPM, Reinato LAF, Gaspar GG, Prado MA do, Gir E. Staphylococcus aureus In Nursing Professionals And The Microorganism's Susceptibility Profile To Antimicrobials. Texto Context - Enferm. 2017;26(2):1-8.

11. Price JR, Cole K, Bexley A, et al. Transmission of Staphylococcus aureus between health-care workers, the environment, and patients in an intensive care unit: a longitudinal cohort study based on whole-genome sequencing. Lancet Infect Dis. 2017;17(2):207-214.

12. Okamo B, Moremi N, Seni J, Mirambo MM, Kidenya BR, Mshana SE. Prevalence and antimicrobial susceptibility profiles of Staphylococcus aureus nasal carriage among pre-clinical and clinical medical students in a Tanzanian University Microbiology. BMC Res Notes. 2016;9(47):1-6. 
13. Shibabaw A, Abebe T, Mihret A. Nasal carriage rate of methicillin resistant Staphylococcus aureus among Dessie Referral Hospital Health Care Workers; Dessie, Northeast Ethiopia. Antimicrob Resist Infect Control. 2013;2(25):1-5.

14. Bauer AW, Kirby WM, Sherris JC, Turck M. Antibiotic susceptibility testing by a standardized single disk method. Am J Clin Pathol. 1966.

15. Clinical and Laboratory Standards Institute (CLSI). M100Ed28 | Performance Standards for Antimicrobial Susceptibility Testing, 28th Edition.; 2018.

16. Mota FS da, Oliveira HA de, Souto RCF. Perfil e prevalência de resistência aos antimicrobianos de bactérias Gram negativas isoladas de pacientes de uma unidade de terapia intensiva. Rev Bras Análises Clínicas. 2018;50(3).

17. Stepanović S, Vuković D, Dakić I, Savić B, Švabić-Vlahović M. A modified microtiter-plate test for quantification of staphylococcal biofilm formation. J Microbiol Methods. 2000;40(2):175-179.

18. Christensen GD, Simpson WA, Younger JJ, et al. Adherence of coagulase-negative staphylococci to plastic tissue culture plates: a quantitative model for the adherence of staphylococci to medical devices. J Clin Microbiol. 1985;22(6):996-1006.

19. Queipo-Ortuño MI, De Dios Colmenero J, Macias M, Bravo MJ, Morata P. Preparation of bacterial DNA template by boiling and effect of immunoglobulin $\mathrm{g}$ as an inhibitor in real-time PCR for serum samples from patients with brucellosis. Clin Vaccine Immunol. 2008;15(2):293-296.

20. Geha DJ, Uhl JR, Gustaferro CA, Persing DH. Multiplex PCR for identification of methicillin-resistant staphylococci in the clinical laboratory. J Clin Microbiol. 1994.

21. Lina G, Piémont Y, Godail-Gamot F, et al. Involvement of Panton-Valentine leukocidin-producing Staphylococcus aureus in primary skin infections and pneumonia. Clin Infect Dis. 1999;29(5):1128-1132.

22. Becker K, Roth R, Peters G. Rapid and specific detection of toxigenic Staphylococcus aureus: Use of two multiplex PCR enzyme immunoassays for amplification and hybridization of staphylococcal enterotoxin genes, exfoliative toxin genes, and toxic shock syndrome toxin 1 gene. J Clin Microbiol. 1998;36(9):2548-2553.

23. Harmsen D, Claus H, Witte W, Claus H, Turnwald D, Vogel U. Typing of Methicillin-Resistant Staphylococcus aureus in a University Hospital Setting by Using Novel Software for spa Repeat Determination and Database Management. J Clin Microbiol. 2003;41(12):5442-5448.

24. Kalorey DR, Shanmugam Y, Kurkure NV, Chousalkar KK, Barbuddhe SB. PCR-based detection of genes encoding virulence determinants in Staphylococcus aureus from bovine subclinical mastitis cases. J Vet Sci. 2007;8(2):151-154.

25. Pereyra EAL, Picech F, Renna MS, et al. Detection of Staphylococcus aureus adhesion and biofilm-producing genes and their expression during internalization in bovine mammary epithelial cells. Vet Microbiol. 2016;183(1):69-77.

26. Moosavian M, Shahin M, Navidifar T, Torabipour M. Typing of staphylococcal cassette chromosome mec encoding methicillin resistance in Staphylococcus aureus isolates in Ahvaz, Iran. New Microbes New Infect. 2018;21:90-94.

27. Olsen K, Sangvik M, Simonsen GS, et al. Prevalence and population structure of Staphylococcus aureus nasal carriage in healthcare workers in a general population. The Troms $\varnothing$ Staph and Skin Study. Epidemiol Infect. 2013;141(1):143-152.

28. da Silva LSC, Andrade YMFS, Oliveira AC, et al. Prevalence of methicillin-resistant Staphylococcus aureus colonization among healthcare workers at a tertiary care hospital in northeastern Brazil. Infect Prev Pract. 2020;2(4):100084.

29. Reinato LAF, Pereira FMV, Lopes LP, Pio DPM, Gir E. Nasal colonization in nursing professionals from units specialized in HIV/AIDS. Rev Bras Enferm. 2015;68(2):292-296.

30. Elie-Turenne M-C, Fernandes H, Mediavilla JR, et al. Prevalence and Characteristics of Staphylococcus aureus Colonization among Healthcare Professionals in an Urban Teaching Hospital. Infect Control Hosp Epidemiol. 2010;31(6):574-580.

31. Al-Zoubi MS, Al-Tayyar IA, Hussein E, Jabali A Al, Khudairat S. Antimicrobial susceptibility pattern of Staphylococcus aureus isolated from clinical specimens in Northern area of Jordan. Iran J Microbiol. 2015;7(5):265-272.

32. Hong S-N, Kim J, Sung H-H. Differences in the Antibiotic Resistance Pattern of Staphylococcus aureus Isolated by Clinical Specimens in a University Hospital in South Korea. Korean J Clin Lab Sci. 2018;50(2):85-92.

33. Navidinia M, Fallah F, Lajevardi B, Shirdoost M, Jamali J. Epidemiology of Methicillin-Resistant Staphylococcus aureus Isolated From Health Care Providers in Mofid Children Hospital. Arch Pediatr Infect Dis. 2015;3(2):e16458. 
34. Gurung RR, Maharjan P, Chhetri GG. Antibiotic resistance pattern of Staphylococcus aureus with reference to MRSA isolates from pediatric patients. Futur Sci OA. 2020;6(4).

35. Hoffmann K, den Heijer CDJ, George A, Apfalter P, Maier M. Prevalence and resistance patterns of commensal Staphylococcus aureus in community-dwelling GP patients and socio-demographic associations. A cross-sectional study in the framework of the APRES-project in Austria. BMC Infect Dis. 2015;15(213).

36. Noel G, Benigne B, Vincent M. Prevalence of Staphylococcus aureus among Clinical Isolates and their Responses to Selected Antibiotics at Centre Hospitalier Universitaire de Kigali (CHUK). J Microbiol Exp. 2017;5(4).

37. Khanal R, Sah P, Lamichhane P, Lamsal A, Upadhaya S, Pahwa VK. Nasal carriage of methicillin resistant Staphylococcus aureus among health care workers at a tertiary care hospital in Western Nepal. Antimicrob Resist Infect Control. 2015;4(39). doi:10.1186/s13756-015-0082-3

38. Legese H, Kahsay AG, Kahsay A, et al. Nasal carriage, risk factors and antimicrobial susceptibility pattern of methicillin resistant Staphylococcus aureus among healthcare workers in Adigrat and Wukro hospitals, Tigray, Northern Ethiopia. BMC Res Notes. 2018;11(1):1-6. doi:10.1186/s13104-018-3353-2

39. Joachim A, Moyo SJ, Nkinda L, et al. Nasal Carriage of Methicillin-Resistant Staphylococcus aureus among Health Care Workers in Tertiary and Regional Hospitals in Dar es Salam, Tanzania. Int J Microbiol. 2018;2018:5058390. doi:10.1155/2018/5058390

40. Saderi H, Emadi B, Owlia P. Phenotypic and genotypic study of macrolide, lincosamide and streptogramin B (MLSB) resistance in clinical isolates of Staphylococcus aureus in Tehran, Iran. Med Sci Monit. 2011;17(2):48-53. doi:10.12659/msm.881386

41. Khatri S, Pant ND, Bhandari R, et al. Nasal Carriage Rate of Methicillin Resistant Staphylococcus aureus among Health Care Workers at a Tertiary Care Hospital in Kathmandu, Nepal. J Nepal Health Res Counc. 2017;15(35):26-30.

42. Omuse G, Kariuki S, Revathi G. Unexpected absence of meticillin-resistant Staphylococcus aureus nasal carriage by healthcare workers in a tertiary hospital in Kenya. J Hosp Infect. 2012;80(1):71-73.

43. Lee AS, De Lencastre H, Garau J, et al. Methicillin-resistant Staphylococcus aureus. Nat Rev Dis Prim. 2018;4(May):1-23.

44. Albrich WC, Harbarth S. Health-care workers: source, vector, or victim of MRSA? Lancet Infect Dis. 2008;8(5):289-301.

45. Vieira MA, Minamisava R, Pessoa-Júnior V, et al. Methicillin-resistant Staphylococcus aureus nasal carriage in neonates and children attending a pediatric outpatient clinics in Brazil. Brazilian J Infect Dis. 2014;18(1):42-47.

46. Shariati A, Dadashi M, Moghadam MT, van Belkum A, Yaslianifard S, Darban-Sarokhalil D. Global prevalence and distribution of vancomycin resistant, vancomycin intermediate and heterogeneously vancomycin intermediate Staphylococcus aureus clinical isolates: a systematic review and meta-analysis. Sci Rep. 2020;10(12689):1-16.

47. Juhlin A, Svensson S, Thomsen P, Trobos M. Staphylococcal biofilm gene expression on biomaterials - A methodological study. J Biomed Mater Res A. 2017;105(12):3400-3412.

48. Indrawattana N, Sungkhachat O, Sookrung N, et al. Staphylococcus aureus Clinical Isolates: Antibiotic Susceptibility, Molecular Characteristics, and Ability to Form Biofilm. Makino S, org. Biomed Res Int. 2013;2013:314654. doi:10.1155/2013/314654

49. Marques VF, Motta CC da, Soares B da S, et al. Biofilm production and beta-lactamic resistance in Brazilian Staphylococcus aureus isolates from bovine mastitis. Brazilian J Microbiol. 2017;48(1):118-124.

50. Nasr RA, AbuShady HM, Hussein HS. Biofilm formation and presence of icaAD gene in clinical isolates of staphylococci. Egypt J Med Hum Genet. 2012;13(3):269-274.

51. Omidi M, Firoozeh F, Saffari M, Sedaghat H, Zibaei M, Khaledi A. Ability of biofilm production and molecular analysis of spa and ica genes among clinical isolates of methicillin-resistant Staphylococcus aureus. BMC Res Notes. 2020;13(1):1-7.

52. Song F, Koo H, Ren D. Effects of Material Properties on Bacterial Adhesion and Biofilm Formation. J Dent Res. 2015;94(8).

53. Chakolwa G, Samutela MT, Kwenda G, et al. Carriage rate and antimicrobial resistance profiles of Staphylococcus aureus among healthcare workers at a large tertiary referral hospital in Lusaka, Zambia. Sci African. 2019;5:e00105.

54. Castro A, Komora N, Ferreira V, et al. Prevalence of Staphylococcus aureus from nares and hands on healthcare professionals in a Portuguese Hospital. J App/ Microbiol. 2016;121.

Page 15/17 
55. Papadimitriou-Olivgeris M, Drougka E, Fligou F, et al. Spread of Tst-Positive Staphylococcus aureus Strains Belonging to ST30 Clone among Patients and Healthcare Workers in Two Intensive Care Units. Toxins (Basel). 2017;9(9):270.

56. Sauer P, Síla J, Štosová T, et al. Prevalence of genes encoding extracellular virulence factors among meticillin-resistant Staphylococcus aureus isolates from the University Hospital, Olomouc, Czech Republic. J Med Microbiol. 2008;57(4):403410.

57. Hematian A, Monjezi A, Abiri R, et al. Clonal lineage diversity, antibiotic resistance, and virulence determinants among methicillin-resistant and methicillin-susceptible Staphylococcus aureus isolated from nurses at a teaching hospital in ilam, Iran: Successful nares decolonization by mupiroc. J Glob Infect Dis. 2018;20(2):67-73.

58. Oliveira D, Borges A, Simões M. Staphylococcus aureus Toxins and Their Molecular Activity in Infectious Diseases. Toxins (Basel). 2018;10(6):252.

59. Labandeira-Rey M, Couzon F, Boisset S, et al. Staphylococcus aureus Panton-Valentine Leukocidin Causes Necrotizing Pneumonia. Science (80). 2007;315(5815):1130 LP - 1133.

60. de Carvalho SP, de Almeida JB, Andrade YMFS, et al. Molecular characteristics of methicillin-resistant Staphylococcus aureus isolates from hospital and community environments in northeastern Brazil. Brazilian J Infect Dis. 2019;23(2):134-138.

\section{Figures}

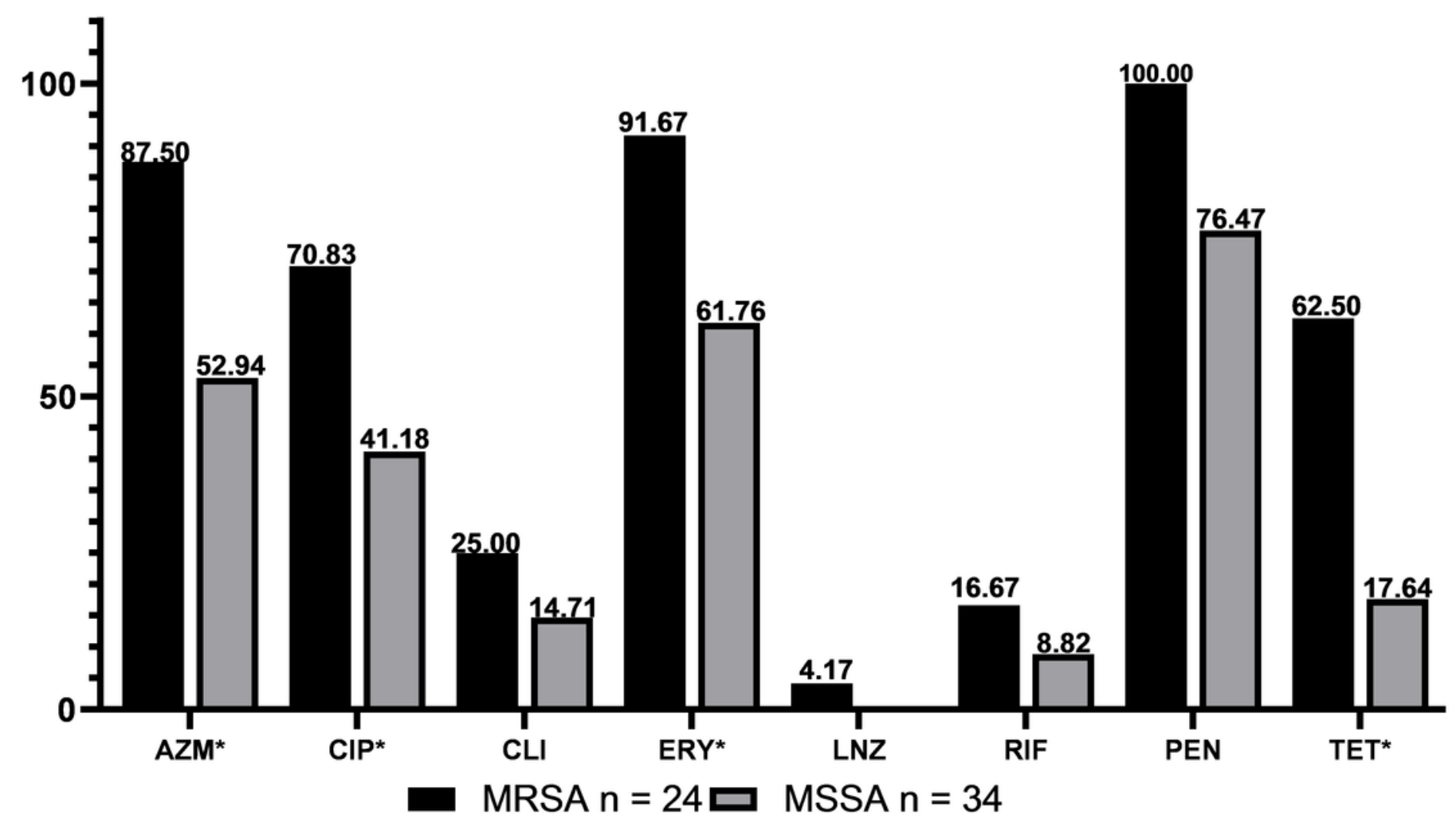

Figure 1

Antibiotic resistance profiles of methicillin-susceptible and methicillin-resistant $\mathrm{S}$. aureus isolated from nursing staff. PEN, Penicillin; AZM, Azithromycin; ERY, Erythromycin; CIP, Ciprofloxacin; RIF, Rifampin; TET, Tetracycline; LZD, Linezolid; MRSA, methicillin-resistant Staphylococcus aureus; MSSA, methicillin-susceptible S. aureus. *statistically significant $(p$ value $<0.05)$. Note: MRSA isolates are considered resistant to penicillin, statistics not applicable. 
(a)

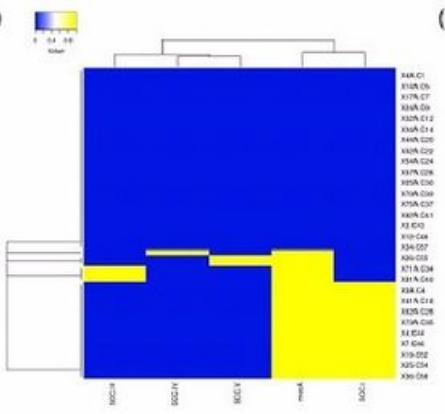

(d)

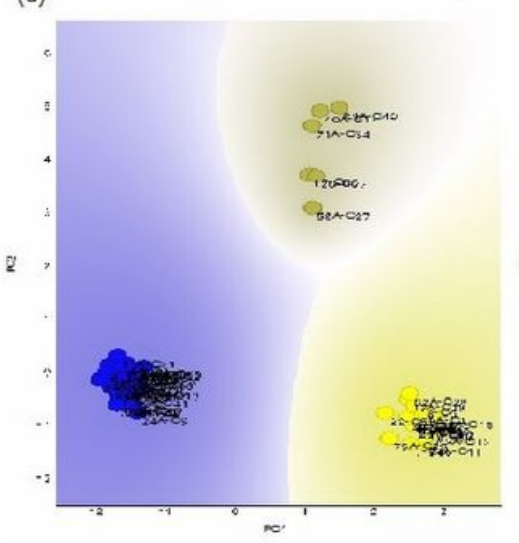

(b)

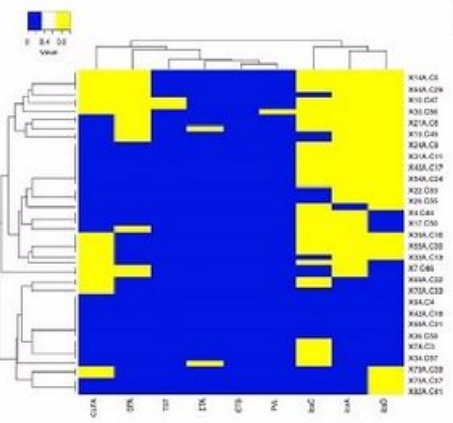

(e) (c)

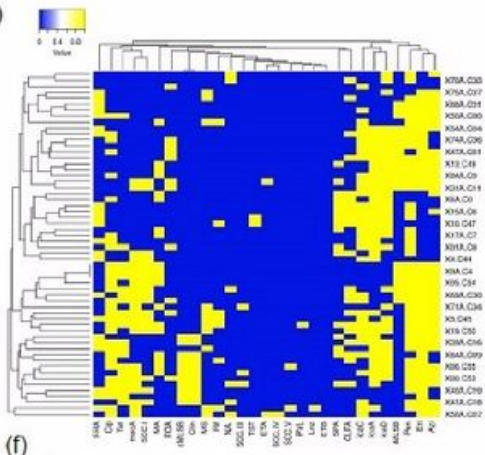

\section{Figure 2}

S. aureus strain clustering Based on our data, the interrelationship and clustering of S. aureus strains can be found in Figure 2 . The heat maps show that different clusters (groups) were formed for strains with similar characteristics in terms of resistance (a), virulence (b) and the whole dataset (phenotypic and genotypic). The PCA analysis reinforces the heat map results, demonstrating the formation of different groups according to the above-mentioned characteristics: resistance (d), virulence (e) and for the whole dataset (phenotypic and genotypic). This data therefore demonstrates the diversity of S. aureus strains isolated from healthcare workers, as highlighted by the formation of 3 main groups.

\section{Supplementary Files}

This is a list of supplementary files associated with this preprint. Click to download.

- SUPPLEMENTARYFIGURES.docx 